\title{
Developing Correlations for Advance Prediction of Slope Factor of Safety Using Linear Regression Analysis - Karachi Landslide as a Case Study
}

\author{
Shuhong Wang, Muhammad Israr Khan* \\ School of Resources and Civil Engineering, Northeastern University, China
}

Received: 2 February 2021

Accepted: 8 April 2021

\begin{abstract}
This study examines the slope stability analysis of a soil slope to correlate the Factor of Safety (FS) with the slope angle ( $\beta$ ). Using linear regression analysis, a study is performed to predict FS for slopes in different conditions, such as saturated, unsaturated, seismic and non-seismic states. A total of 400 analysis are performed. The mechanical properties of slope is taken from the experimental analysis such as Atterberg limits, sieve analysis, compaction and other required tests. The slope angle is changed linearly and FS is calculated to develop correlations. In seismic analysis, the horizontal seismic coefficient is taken as 0.3 , which is the maximum value for horizontal load in case of seismic analysis. The coefficient of determination $\left(\mathrm{R}^{2}\right)$ for all the developed equations is higher than $99 \%$. All the developed correlations are provided in the results section. These correlations are applicable in slope stability projects to find the slope safety in advance. A landslide in Karachi is considered as a case study and these correlations are applied to know about the future stability of the slope, which gives perfect result.
\end{abstract}

Keywords: slope stability analysis, saturated and unsaturated, seismic, regression, correlations

\section{Introduction}

Landsliding is a major issue faced by people throughout the world. It causes severe damage not only to properties, roads and buildings but a large number of people lost their lives due to this issue. Therefore experts of this field always trying to know about the main reasons behind landsliding. There are two cases in slope stability analysis.

1. Estimate the stability of any slope before it fails.
2. Estimate the stability after the slope fails.

If any slope is expected to fail, it must be analyzed that how much it is safe? And must be treated so that it remains stable. If it is not treated on time, it may result in huge loss of property as well as human lives like it happened in the past many times. Fig. 1 shows few glimpses of landsliding.

Normally geotechnical engineers are facing major problems in slope stability projects to know about the slope factor of safety. The soil behavior depends on many parameters, i.e. cohesion, friction, unit weight, moisture content, ground geology and temperature etc. Therefore, geotechnical engineers are always busy investigating of soil behavior, keeping all 


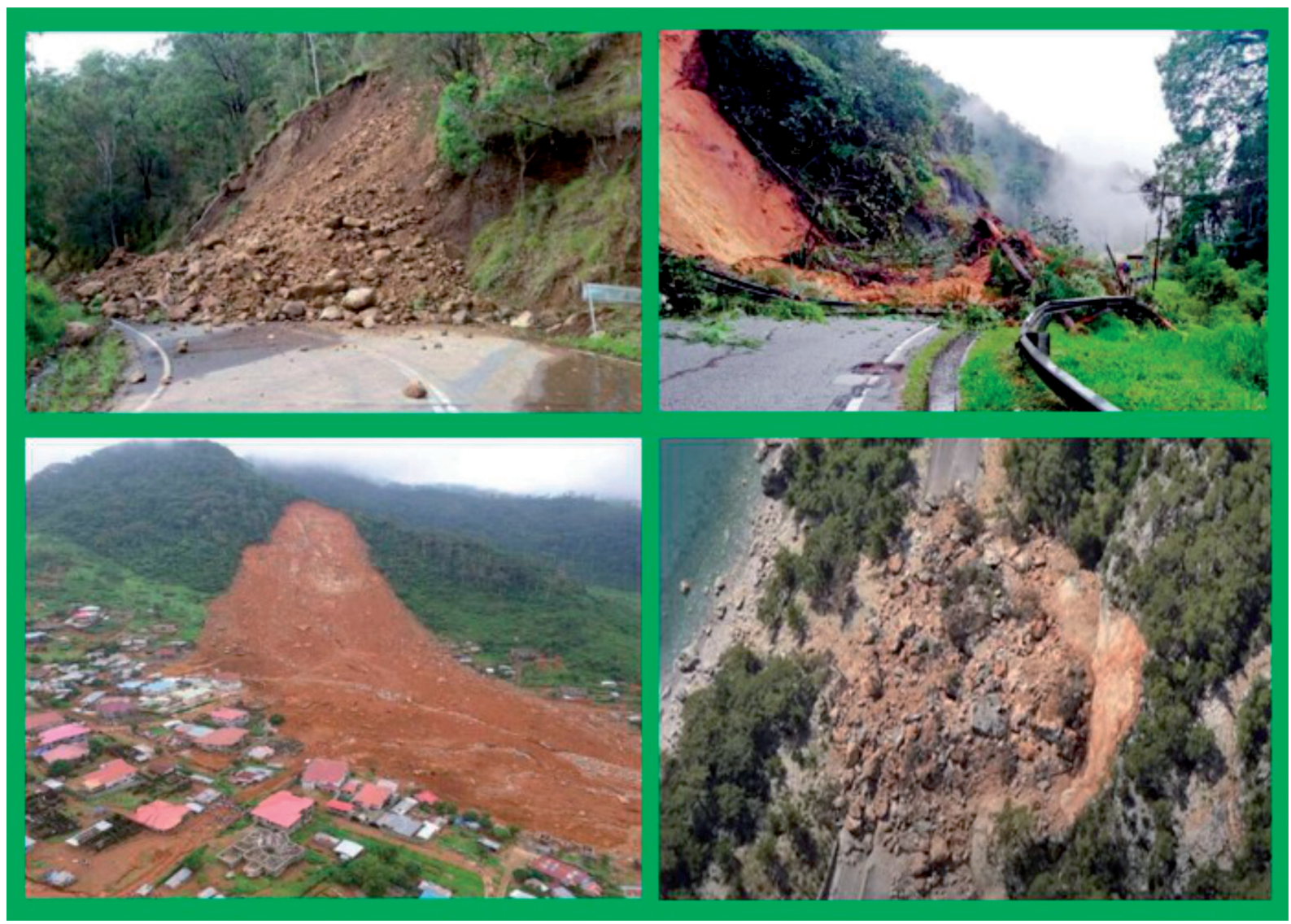

Fig. 1. Landsliding.

the different parameters in considerations. In this regard, many researchers and investigators provided different techniques and formulas to predict the slope factor of safety in advance. An Artificial Neural Network was used to find out the correlations between different parameters of slope [1]. The results were compared with Hoek and Bray [2] which shows the results to be very satisfactory. To study the stability prediction of Letlhakane mine, some researchers also used the geomos slope monitoring system. The geomos slope monitoring system is a continuous and automatic system which runs for 24 hours. Evolutionary Polynomial Technique (EPR) was developed to predict the FS [3]. This model was very useful in predicting the behavior of slopes for analyzing FS. Later Geo Studio was used and compared with the fuzzy logic system $[4,5]$. The results were found very close to the target. In another work, as artificial neural network and multiple linear regression to calculate the FS in case of a typical artificial slope [6]. This slope was also subjected to seismic forces. The predicted results showed that the results were highly precise. Another researcher developed equations considering the depth ratio in case of rainfall induced slopes [7]. The results were compared with the previous steady state hydrological model and landslide inventory graphs, they concluded that the predicted approach gives very satisfactory results. Using the theory of mass approach, the run out distance of rotational type slope was predicted in other work [8]. They concluded that the unit weight plays a very important role in the factor of safety issues. In another analysis it was concluded that the Chaancun Landslide was triggered by the excavation of the slope toe and the landslide was a partial revival of an ancient landslide and was a thrust load-caused landslide [9]. Other researchers worked on same issue to determine the slope safety by considering different parameters which affect the slope [10-16].

Most of the previous work is based on slope stability analysis of already failed slope. In landsliding issues, it is required to know about the slope stability in advance. Or if any slope already exist and seems to be risky, it must be analyzed and treated such that the stability gets increased. Moreover the slope factor of safety varies with different slope angles $(\beta)$. Fig. 2 shows the slope model considered in this research.

In this paper, prediction equations are developed using multiple linear regression. A software namely Statistical Package for the Social Sciences (SPSS) is used to find the correlations of FS and slope angle. This software is basically used for analyzing complex data and one of the main purpose is to make correlations between different variables. SPSS can do linear as well as non-linear analysis. Fig. 3 shows the flowchart of the methodology of this paper: 


\begin{tabular}{|c|c|c|}
\hline \multicolumn{3}{|c|}{ Coordinates } \\
\hline Point & X & Y \\
\hline 1 & 0 & 0 \\
\hline 2 & 27 & 0 \\
\hline 3 & 27 & 5 \\
\hline 4 & 16 & 5 \\
\hline 5 & $\begin{array}{c}\text { Varies with every } \\
\text { angle (70-88) }\end{array}$ & 16 \\
\hline 6 & 0 & 16 \\
\hline
\end{tabular}

6 5

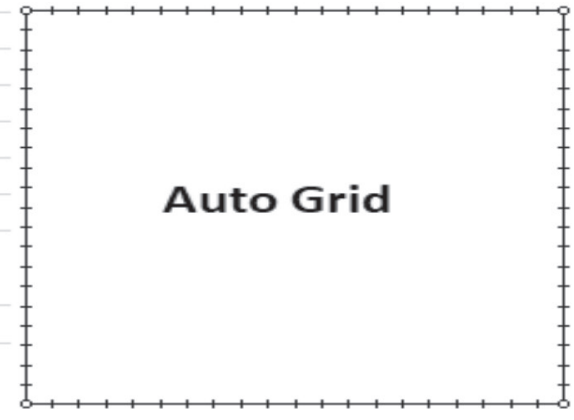

1

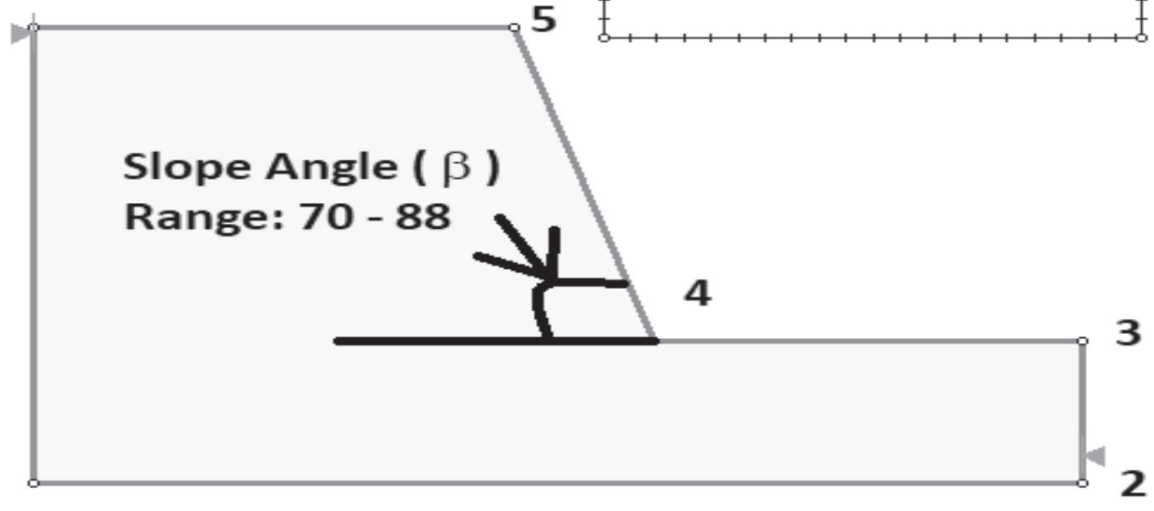

Fig. 2. Slope model with coordinates.

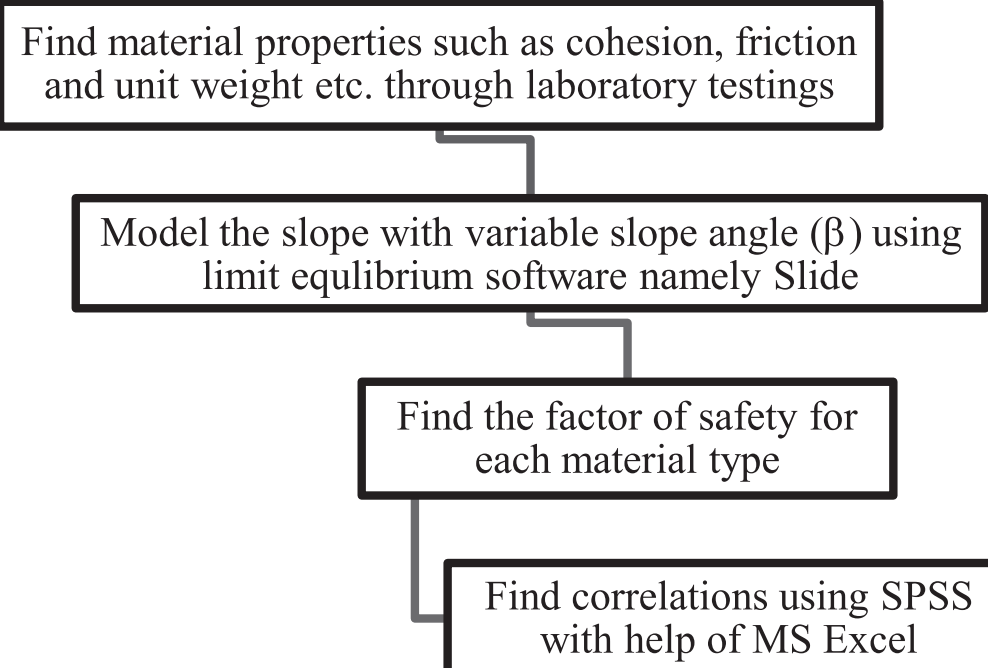

Fig. 3. Paper methodology flowchart.

\section{Material and Methods}

Local Chinese site is considered for the material to be analyzed. After all the necessary experiments, such as Atterberg limits, moisture content test, triaxial test and all other necessary tests, details of the material properties achieved are given in Table 1. In this table, material 1 to 5 is pure clay while material 6 to 10 is clayey sand. The slope angle $(\beta)$ range is 70 to 88 degrees. It is because the most critical slope angle is in range of 60 to 90 degrees.

Ten number of different material types were considered and for each material type, slope angle is changed from 70 to 88 degrees. Hence a total number of four hundred analysis are performed. All this analysis is performed in five phases.

Phase 1: Unsaturated non-seismic analysis

Phase 2: Saturated non-seismic analysis

Phase 3: Unsaturated seismic analysis

Phase 4: Saturated seismic analysis

Phase 5: Case study - Landslide in Karachi, Pakistan

In all these phases, correlations between FS and $\beta$ are developed. The applicability of these equations is very useful as the FS have a very close relation with $\beta$. 
Table 1. Material properties.

\begin{tabular}{|c|c|c|c|c|}
\hline Material Number & Cohesion $(\mathrm{KPa})$ & Friction $(\phi)$ & Unit Weight $\left(\mathrm{KN} / \mathrm{m}^{3}\right)$ & Material Type \\
\hline 1 & 15.1 & 31 & 16.5 & Clay \\
\hline 2 & 16.6 & 32 & 16.4 & Clay \\
\hline 3 & 17.5 & 33 & 17.3 & Clay \\
\hline 4 & 18.5 & 34 & 17.7 & Clay \\
\hline 5 & 19.3 & 35 & 18.5 & Clayey Sand \\
\hline 6 & 1.3 & 26 & 16.6 & Clayey Sand \\
\hline 7 & 2.4 & 27 & 16.7 & Clayey Sand \\
\hline 8 & 3.5 & 28 & 16.8 & Clayey Sand \\
\hline 9 & 4.5 & 29 & 16.9 & Clayey Sand \\
\hline 10 & 5.8 & 30 & & \\
\hline
\end{tabular}

\section{Results and Discussion}

\section{Unsaturated Non-Seismic Analysis}

Fig. 4 shows the slope model considered in phase 1 .

Table 2 shows the factor of safety values achieved in all the hundred analysis for different material types and varying slope angles.
Table 3 and 4 shows the correlation equations in case of clay and clayey sand respectively for all the ten types of materials in case of unsaturated non-seismic state.

From Table 3, the final average correlation between FS and $\beta$ in case of clay came out to be:

$$
\mathrm{FS}=1.836-0.011^{*} \beta
$$

\section{Slope Model: Unsaturated Case Material Properties: Table 1 FS: Table 2}
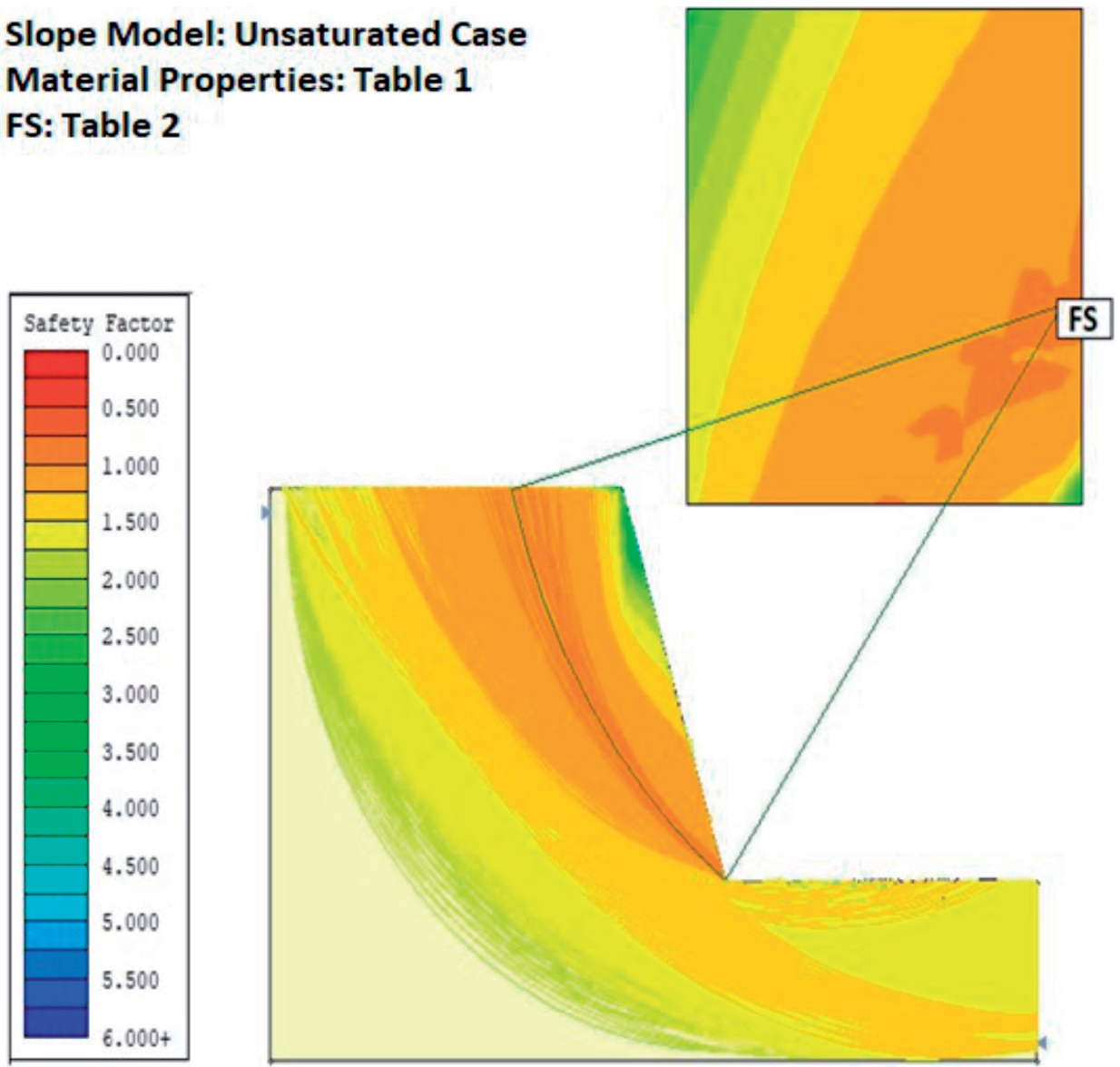

Fig. 4. Slope model - Unsaturated non-seismic case. 
Table 2. FS in case of unsaturated non-seismic analysis.

\begin{tabular}{|c|c|c|c|c|c|c|c|c|c|c|}
\hline \multirow{2}{*}{ Slope angle $(\beta)$} & \multicolumn{10}{|c|}{ Factor of Safety (FS) } \\
\cline { 2 - 14 }$y$ & M1 & M2 & M3 & M4 & M5 & M6 & M7 & M8 & M9 & M10 \\
\hline 70 & 0.971 & 1.043 & 1.062 & 1.1 & 1.118 & 0.317 & 0.397 & 0.467 & 0.528 & 0.599 \\
\hline 72 & 0.948 & 1.021 & 1.038 & 1.074 & 1.091 & 0.309 & 0.38 & 0.451 & 0.51 & 0.581 \\
\hline 74 & 0.92 & 0.991 & 1.007 & 1.043 & 1.059 & 0.295 & 0.37 & 0.434 & 0.492 & 0.563 \\
\hline 76 & 0.897 & 0.964 & 0.981 & 1.016 & 1.033 & 0.288 & 0.363 & 0.423 & 0.477 & 0.543 \\
\hline 78 & 0.878 & 0.943 & 0.96 & 0.994 & 1.012 & 0.278 & 0.352 & 0.417 & 0.467 & 0.529 \\
\hline 80 & 0.862 & 0.927 & 0.943 & 0.976 & 0.992 & 0.271 & 0.347 & 0.407 & 0.461 & 0.519 \\
\hline 82 & 0.843 & 0.906 & 0.922 & 0.955 & 0.971 & 0.266 & 0.338 & 0.401 & 0.451 & 0.513 \\
\hline 84 & 0.819 & 0.883 & 0.897 & 0.929 & 0.943 & 0.264 & 0.333 & 0.393 & 0.445 & 0.503 \\
\hline 86 & 0.8 & 0.862 & 0.876 & 0.907 & 0.921 & 0.259 & 0.33 & 0.387 & 0.438 & 0.497 \\
\hline 88 & 0.785 & 0.844 & 0.859 & 0.889 & 0.904 & 0.256 & 0.328 & 0.384 & 0.432 & 0.49 \\
\hline
\end{tabular}

Table 3. Correlations in case of clay - unsaturated non-seismic case.

\begin{tabular}{|c|c|c|c|c|c|}
\hline \multicolumn{5}{|c|}{ Clay } \\
\hline & M1 & M2 & M3 & M4 & M5 \\
\hline FS & $1.685-0.010 * \mathrm{~b}$ & $1.808-0.011 * \mathrm{~b}$ & $1.841-0.011 * \mathrm{~b}$ & $1.907-0.012 * \mathrm{~b}$ & $1.939-0.012 * \mathrm{~b}$ \\
\hline
\end{tabular}

Table 4. Correlations in case of clayey sand - unsaturated non-seismic case.

\begin{tabular}{|c|c|c|c|c|c|}
\hline \multicolumn{5}{|c|}{ Clayey Sand } \\
\hline & M6 & M7 & M8 & M9 & M10 \\
\hline FS & $0.550-0.003 * \mathrm{~b}$ & $0.650-0.004 * \mathrm{~b}$ & $0.770-0.004 * \mathrm{~b}$ & $0.874-0.005 * \mathrm{~b}$ & $1.005-0.006 * \mathrm{~b}$ \\
\hline
\end{tabular}

Table 5. Factor of Safety Criteria from U.S. Army Corps of Engineers'.

\begin{tabular}{|c|c|c|c|}
\hline & \multicolumn{3}{|c|}{ Required factor of safeties (a) } \\
\hline Types of slopes & $\begin{array}{c}\text { For end of construction } \\
\text { (b) }\end{array}$ & $\begin{array}{c}\text { For long - term steady } \\
\text { seepage }\end{array}$ & $\begin{array}{c}\text { For rapid draw down } \\
\text { (c) }\end{array}$ \\
\hline $\begin{array}{c}\text { Slopes of dams, levees, and dikes, and other } \\
\text { embankment and excavation slopes (c) }\end{array}$ & 1.3 & 1.5 & 1 to 1.2 \\
\hline
\end{tabular}

(a) For slopes where either sliding or large deformations have occurred, and back analyses have been performed to establish design shear strengths, lower factors of safety may be used. In such cases probabilistic analyses may be useful in supporting the use of lower factors of safety for design. Lower factors of safety may also be justified when the consequences of failure are small.

(b) Stability would be inadequate. Special care, and possibly higher factors of safety, should be used in such cases.

(c) Temporary excavated slopes are sometimes designed only for short-term stability, with knowledge that long-term FS $=1.0$ applies to drawdown from maximum surcharge pool, for conditions where these water levels are unlikely to persist for long enough to establish steady seepage. FS = 1.2 applies to maximum storage pool level, likely to persist for long periods prior to drawdown. For slopes in pumped storage projects, where rapid drawdown is a normal operating condition, higher factors of safety (e.g., 1.3 to 1.4) should be used. In case the FS is not in the range then it can be achieved by increasing or decreasing the value of $\beta$ using equation 1 and 2 .

Also from Table 4, the final average correlation between FS and $\beta$ in case of clayey sand came out to be:

$$
\mathrm{FS}=0.77-0.004 * \beta
$$

The coefficient of determination R2 in equation 1 and 2 is $99.5 \%$ which shows the variables are best correlated with each other.

In most of the cases, the FS value is less than 1. And less than 1 means the slope is a failed slope. The FS 
Table 6. Shear strength in case of unsaturated non-seismic analysis.

\begin{tabular}{|c|c|c|c|c|c|}
\hline \multirow{2}{*}{$\beta$} & \multicolumn{5}{|c|}{ SS } \\
\cline { 2 - 6 } & M1 & M2 & M3 & M4 & M5 \\
\hline 70 & 44.702 & 47.2 & 51 & 54.12 & 57.98 \\
\hline 72 & 41.422 & 43.8 & 47.3 & 50.2 & 53.7 \\
\hline 74 & 42.8 & 45.26 & 48.9 & 51.9 & 55.5 \\
\hline 76 & 47.13 & 49.7 & 53.8 & 57.1 & 61.15 \\
\hline 78 & 51.5 & 54.2 & 58.7 & 62.3 & 66.8 \\
\hline 80 & 47.4 & 57.8 & 54 & 57.4 & 61.5 \\
\hline 82 & 52.1 & 54.9 & 59.4 & 63 & 67.7 \\
\hline 84 & 49.6 & 52.2 & 56.6 & 57.2 & 64.3 \\
\hline 86 & 54.6 & 57.4 & 59.6 & 66.1 & 70.9 \\
\hline 88 & 59.7 & 62.7 & 68 & 72.2 & 77.6 \\
\hline
\end{tabular}

criteria by US corps of engineers is given in Table 5 [17].

\section{Maximum Shear Strength Variation with Slope Angle}

The shear strength of these materials can be characterized by the equation.

$$
\mathrm{SS}=\sigma^{\prime} \tan \phi^{\prime}
$$

...where SS is the shear strength, $\sigma^{\prime}$ the effective normal stress on the failure plane, and $\phi^{\prime}$ the effective stress angle of internal friction. Measuring or estimating the drained strengths of these materials involves determining or estimating appropriate values of $\phi$.

$\mathrm{SS}$ is one of the main parameter which is responsible for the stability of any slope. This parameter is directly or indirectly affected by many other parameters such as cohesion, friction, unit weight, pore water pressure, moisture content, particle size and slope angle $(\beta)$. Fig. 5 shows the maximum shear strength graph in case of saturated non-seismic case for material 1 (M1). The maximum shear strength in this case for $\beta$ equals 70 is
44.702 KPa. The distance in meter shows the horizontal distance from 0, 0 coordinate, that is point 1 in Fig. 2 .

Table 6 shows the shear strength values achieved in all the hundred analysis for different material types and varying slope angles.

Table 7 shows the correlation equations in case of clay for all the ten types of materials in case of unsaturated non-seismic state.

From Table 7, the final average correlation between shear strength and $\beta$ in case of clay came out to be:

$$
\text { Shear strength }=-16.686+0.92 * \beta
$$

The factor of safety, FS, is defined with respect to the shear strength of the soil as:

$$
\mathrm{F}=\frac{s}{\tau}
$$

...where $\mathrm{s}$ is the available shear strength and $\tau$ is the equilibrium shear stress. The equilibrium shear stress is the shear stress required to maintain a just-stable slope and from Eq. (5) may be expressed as:

$$
\tau=\frac{s}{F}
$$

The shear strength can be expressed by the MohrCoulomb equation. If the shear strength is expressed in terms of total stresses, Eq. (6) is written as:

$$
\tau=\frac{c+\sigma \tan \phi}{F}
$$

If the shear strength is expressed in terms of effective stresses (e.g., drained shear strengths are being used), the only change from the above is that Eq. (7) is written in terms of effective stresses as:

$$
\tau=\frac{c /+(\sigma-u) \tan \phi /}{F}
$$

Hence the shear strength can be correlated to all these parameters. Similarly the slope angle $(\beta)$ could be correlated to all these parameters too. The correlations

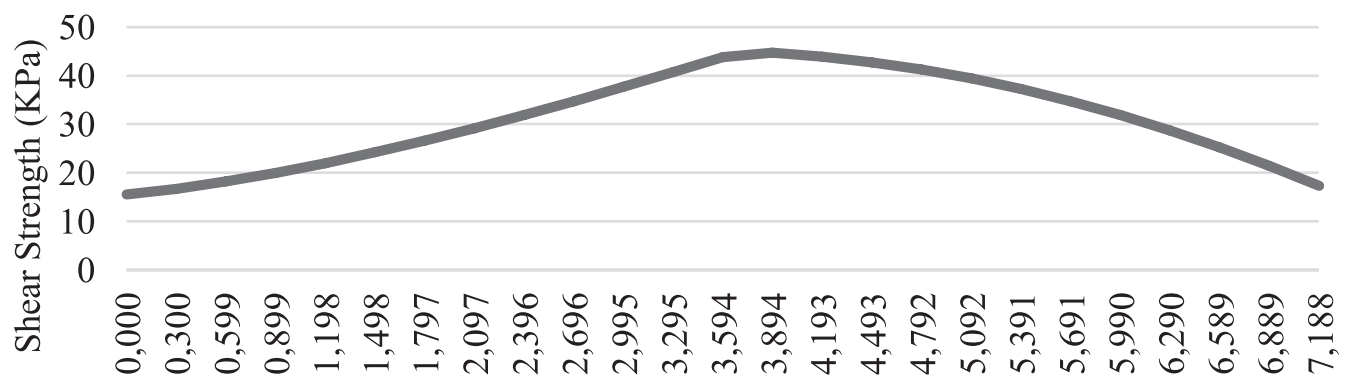

Distance $(m)$

Fig. 5. Shear strength graph in case of unsaturated non-seismic case for material 1 (M1). 
Table 7. Correlations in case of clay - unsaturated non-seismic case.

\begin{tabular}{|c|c|c|c|c|c|}
\hline \multicolumn{6}{|c|}{ Clay } \\
\hline & M1 & M2 & M3 & M4 & M5 \\
\hline SS & $-16.029+0.824 * \beta$ & $-16.573+0.875 * \beta$ & $-13.622+0.878 * \beta$ & $-15.855+0.949 * \beta$ & $-21.351+1.077 * \beta$ \\
\hline
\end{tabular}

Table 8. Correlation among Relative Density, CPT Cone Resistance, and Angle of Internal Friction.

\begin{tabular}{|c|c|c|c|}
\hline State of packing & Relative density $\mathrm{D}_{\mathrm{r}}(\%)$ & Cone resistance & Angle of internal friction \\
\hline Very loose & $<20$ & $<20$ & $32-35$ \\
\hline Loose & $20-40$ & $20-50$ & $35-38$ \\
\hline Medium & $40-60$ & $50-150$ & $38-41$ \\
\hline Dense & $60-80$ & $150-250$ & $41-45$ \\
\hline Very dense & $>80$ & $250-400$ & \\
\hline
\end{tabular}

of relative density, cone resistance and angle of internal friction given in Table 8.

Where:

$$
\mathrm{D}_{\mathrm{r}}=\frac{e_{\max }-e}{e_{\max }-e_{\min }} \times 100
$$

Hence using the above table, the slope angle can be further correlated to angle of internal friction, cone resistance and relative density. Duncan [17] also provided the correlations of state of packing with blow count in Standard Penetration Test (SPT).

\section{Saturated Non-Seismic Analysis}

One of the major causes of landslide is rainfall. It is because the rain water increases the weight of the soil particles and hence decreases the shear strength [18-23]. In second phase of this work, the same slope is analyzed as unsaturated slope. Fig. 6 shows the saturated model.

Table 9 shows the factor of safety values achieved in all the hundred analysis for different material properties and slope angles.

Table 10 and 11 show the correlation equations in case of clay and clayey sand respectively for all the ten types of materials in case of saturated state.

From Table 10, the final average correlation between FS and $\beta$ in case of clay came out to be:

$$
\mathrm{FS}=1.302-0.008 * \beta
$$

Also from Table 11, the final average correlation between FS and $\beta$ in case of clayey sand came out to be:

\section{Slope Model: Saturated Case Material Properties: Table 1 FS: Table 9}

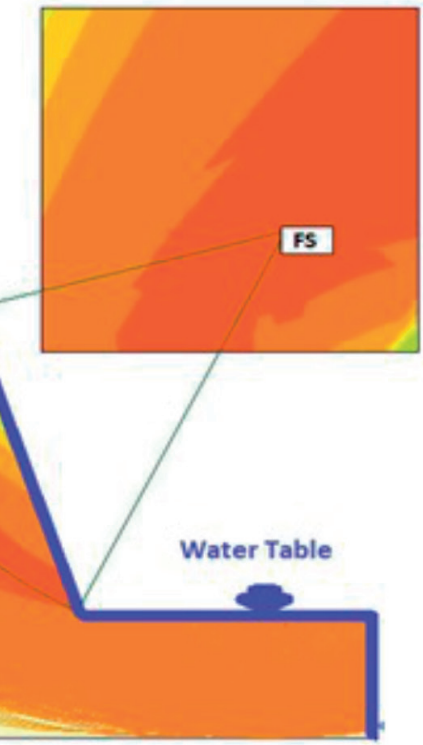

Fig. 6. Slope model - saturated non-seismic case. 
Table 9. FS in case of saturated non-seismic analysis.

\begin{tabular}{|c|c|c|c|c|c|c|c|c|c|c|}
\hline \multirow{2}{*}{$\beta$} & \multicolumn{10}{|c|}{ FS } \\
\cline { 2 - 14 } & M1 & M2 & M3 & M4 & M5 & M6 & M7 & M8 & M9 & M10 \\
\hline 70 & 0.674 & 0.728 & 0.757 & 0.792 & 0.818 & 0.174 & 0.230 & 0.279 & 0.324 & 0.377 \\
\hline 72 & 0.656 & 0.709 & 0.736 & 0.769 & 0.794 & 0.168 & 0.224 & 0.272 & 0.314 & 0.367 \\
\hline 74 & 0.645 & 0.696 & 0.723 & 0.755 & 0.778 & 0.162 & 0.218 & 0.266 & 0.306 & 0.356 \\
\hline 76 & 0.628 & 0.680 & 0.704 & 0.736 & 0.757 & 0.158 & 0.211 & 0.259 & 0.301 & 0.348 \\
\hline 78 & 0.614 & 0.663 & 0.688 & 0.719 & 0.740 & 0.156 & 0.204 & 0.253 & 0.293 & 0.341 \\
\hline 80 & 0.597 & 0.645 & 0.670 & 0.701 & 0.724 & 0.152 & 0.200 & 0.245 & 0.286 & 0.334 \\
\hline 82 & 0.587 & 0.633 & 0.659 & 0.689 & 0.712 & 0.149 & 0.197 & 0.239 & 0.278 & 0.326 \\
\hline 84 & 0.573 & 0.620 & 0.643 & 0.673 & 0.694 & 0.147 & 0.195 & 0.235 & 0.271 & 0.317 \\
\hline 86 & 0.559 & 0.605 & 0.627 & 0.655 & 0.675 & 0.144 & 0.191 & 0.232 & 0.267 & 0.310 \\
\hline 88 & 0.546 & 0.590 & 0.612 & 0.640 & 0.661 & 0.143 & 0.189 & 0.229 & 0.263 & 0.305 \\
\hline
\end{tabular}

Table 10. Correlations in case of Clay - saturated non-seismic case.

\begin{tabular}{|c|c|c|c|c|c|}
\hline \multicolumn{5}{|c|}{ Clay } \\
\hline & M1 & M2 & M3 & M4 & M5 \\
\hline FS & $1.166-0.007 * \beta$ & $1.258-0.008 * \beta$ & $1.309-0.008 * \beta$ & $1.368-0.008 * \beta$ & $1.410-0.009 * \beta$ \\
\hline
\end{tabular}

Table 11. Correlations in case of Clayey Sand - saturated non-seismic case.

\begin{tabular}{|c|c|c|c|c|c|}
\hline \multicolumn{5}{|c|}{ Clayey Sand } \\
\hline & M6 & M7 & M8 & M9 & M10 \\
\hline FS & $0.288-0.002 * \beta$ & $0.388-0.002 * \beta$ & $0.479-0.003 * \beta$ & $0.561-0.003 * \beta$ & $0.653-0.004 * \beta$ \\
\hline
\end{tabular}

$$
\mathrm{FS}=0.474-0.003^{*} \beta
$$

The coefficient of determination $\mathrm{R}^{2}$ in equation 3 and 4 is $99.8 \%$ which shows the variables are best correlated with each other.

\section{Unsaturated Seismic Analysis}

Another most critical situation is to find the slope stability in case of earthquake. Normally the horizontal seismic coefficients is considered in the analysis as the vertical seismic coefficient is almost negligible in most of the cases. Therefore in this phase, the seismic analysis is performed in which the horizontal seismic coefficient is considered as the maximum. That is 0.3 horizontal. Fig. 7 shows the slope model assumed in this case.

Table 12 shows the FS in case of unsaturated seismic analysis.

Table 13 and 14 shows the correlation equations in case of clay and clayey sand respectively for all the ten types of materials in case of unsaturated seismic analysis.
From Table 13, the final average correlation between FS and $\beta$ in case of clay came out to be:

$$
\mathrm{FS}=1.22-0.007 * \beta
$$

Also from Table 14, the final average correlation between FS and $\beta$ in case of clayey sand came out to be:

$$
\mathrm{FS}=0.50-0.003 * \beta
$$

The coefficient of determination $\mathrm{R}^{2}$ in equation 5 and 6 is $99.3 \%$ which shows the variables are best correlated with each other.

\section{Saturated Seismic Analysis}

Fig. 8 shows the slope model in this case.

Table 15 shows the FS in case of saturated seismic analysis. 


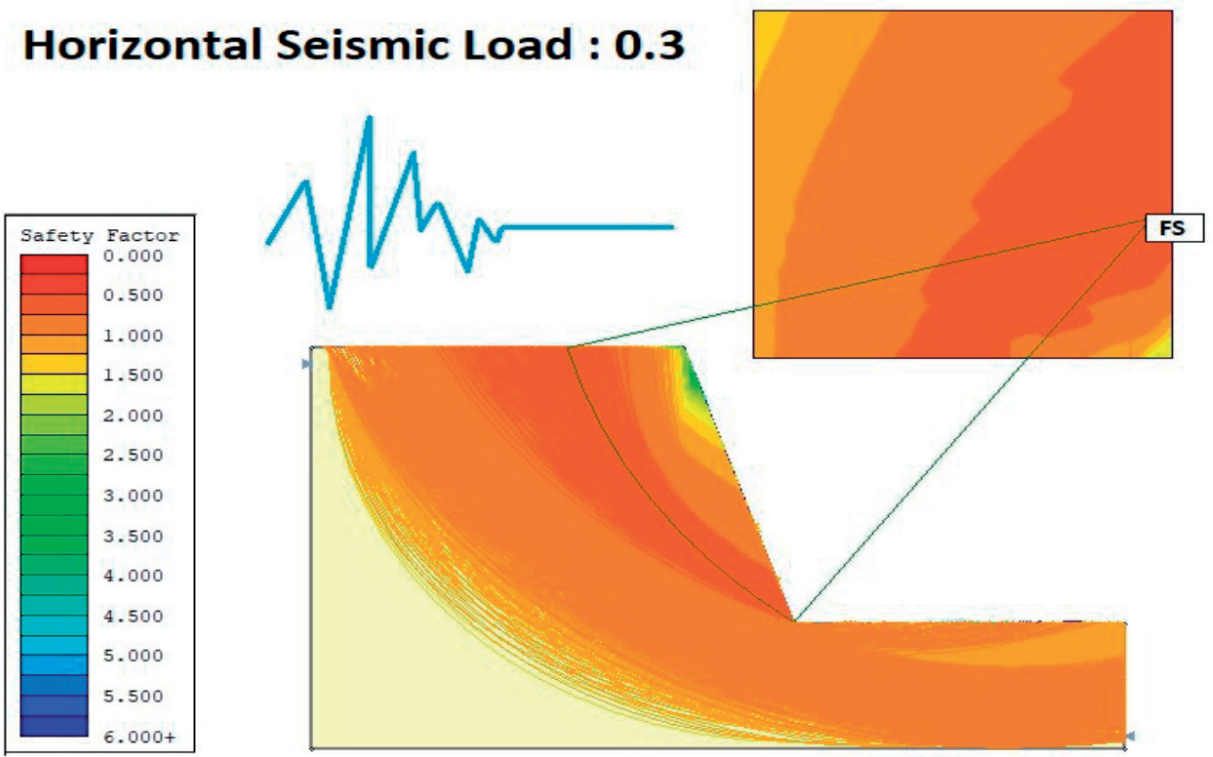

Fig. 7. Slope model - unsaturated seismic case.

Table 12. FS in case of unsaturated seismic analysis.

\begin{tabular}{|c|c|c|c|c|c|c|c|c|c|c|}
\hline \multirow{2}{*}{$\beta$} & \multicolumn{10}{|c|}{ FS } \\
\cline { 2 - 12 }$y$ & M1 & M2 & M3 & M4 & M5 & M6 & M7 & M8 & M9 & M10 \\
\hline 70 & 0.669 & 0.724 & 0.734 & 0.759 & 0.769 & 0.155 & 0.218 & 0.273 & 0.319 & 0.372 \\
\hline 72 & 0.652 & 0.704 & 0.714 & 0.740 & 0.750 & 0.148 & 0.207 & 0.262 & 0.307 & 0.360 \\
\hline 74 & 0.640 & 0.693 & 0.702 & 0.727 & 0.735 & 0.137 & 0.198 & 0.250 & 0.296 & 0.349 \\
\hline 76 & 0.623 & 0.674 & 0.683 & 0.707 & 0.716 & 0.131 & 0.194 & 0.241 & 0.284 & 0.338 \\
\hline 78 & 0.608 & 0.657 & 0.666 & 0.690 & 0.698 & 0.123 & 0.184 & 0.236 & 0.275 & 0.325 \\
\hline 80 & 0.595 & 0.644 & 0.652 & 0.675 & 0.684 & 0.117 & 0.180 & 0.229 & 0.270 & 0.317 \\
\hline 82 & 0.586 & 0.633 & 0.642 & 0.665 & 0.673 & 0.113 & 0.173 & 0.223 & 0.264 & 0.312 \\
\hline 84 & 0.572 & 0.620 & 0.628 & 0.650 & 0.658 & 0.110 & 0.168 & 0.218 & 0.258 & 0.306 \\
\hline 86 & 0.560 & 0.604 & 0.613 & 0.635 & 0.644 & 0.107 & 0.166 & 0.213 & 0.254 & 0.300 \\
\hline 88 & 0.553 & 0.597 & 0.606 & 0.627 & 0.636 & 0.104 & 0.164 & 0.210 & 0.248 & 0.296 \\
\hline
\end{tabular}

Table 13. Correlations in case of clay - unsaturated seismic case.

\begin{tabular}{|c|c|c|c|c|c|}
\hline \multicolumn{6}{|c|}{ Clay } \\
\hline & M1 & M2 & M3 & M4 & M5 \\
\hline FS & $1.121-0.007 * \beta$ & $1.216-0.007 * \beta$ & $1.230-0.007 * \beta$ & $1.274-0.007 * \beta$ & $1.287-0.007 * \beta$ \\
\hline
\end{tabular}

Table 14. Correlations in case of clayey sand - unsaturated seismic case.

\begin{tabular}{|c|c|c|c|c|c|}
\hline \multicolumn{5}{|c|}{ Clayey Sand } \\
\hline & M6 & M7 & M8 & M9 & M10 \\
\hline FS & $0.350-0.003 * \beta$ & $0.422-0.003 * \beta$ & $0.506-0.003 * \beta$ & $0.580-0.004 * \beta$ & $0.664-0.004 * \beta$ \\
\hline
\end{tabular}




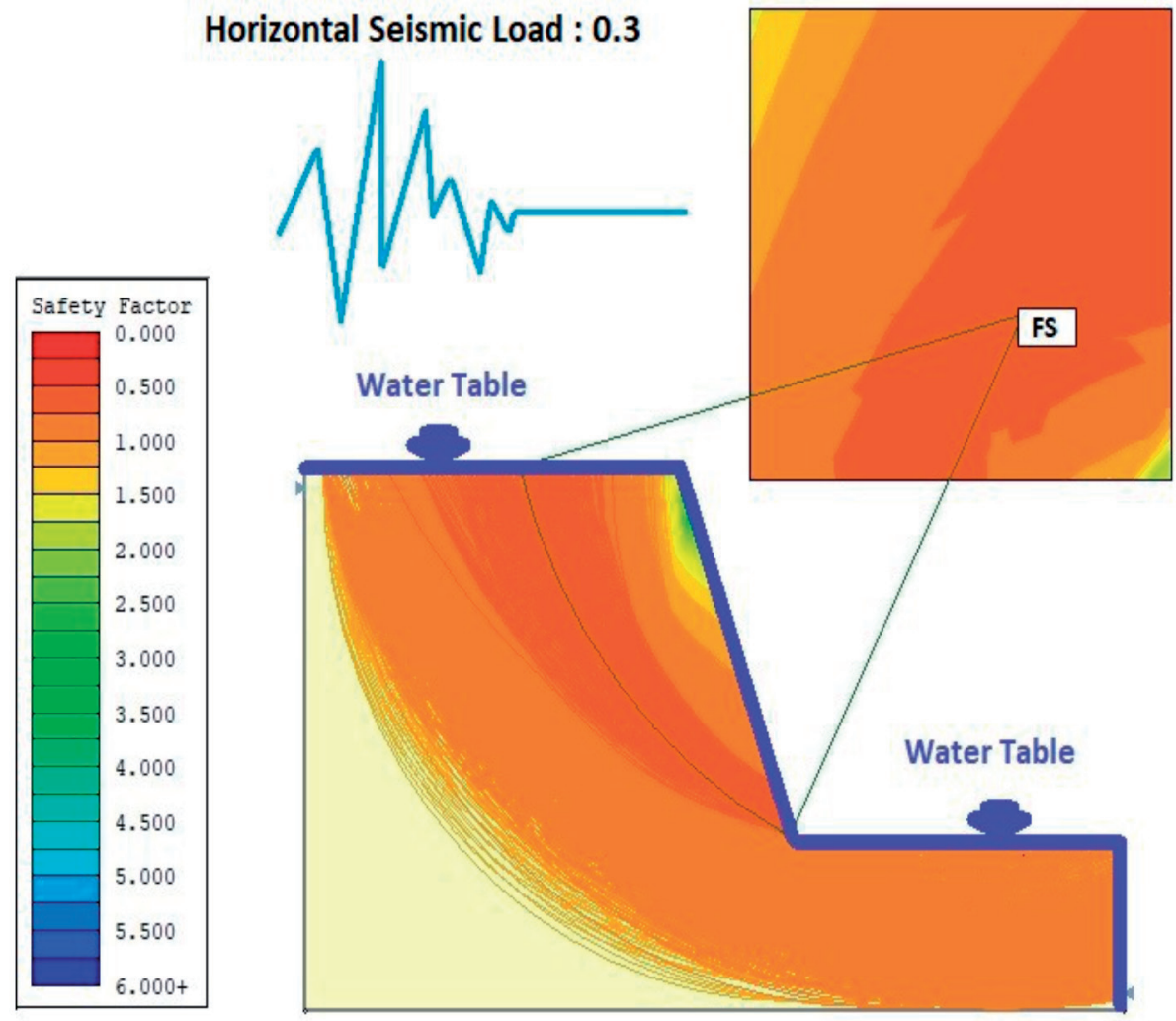

Fig. 8. Slope model - saturated seismic case.

Table 15. FS in case of saturated seismic analysis.

\begin{tabular}{|c|c|c|c|c|c|c|c|c|c|c|}
\hline \multirow{2}{*}{ Slope angle $(\beta)$} & \multicolumn{10}{|c|}{ Factor of Safety (FS) } \\
\cline { 2 - 12 } & M1 & M2 & M3 & M4 & M5 & M6 & M7 & M8 & M9 & M10 \\
\hline 70 & 0.396 & 0.433 & 0.451 & 0.474 & 0.490 & 0.030 & 0.067 & 0.104 & 0.136 & 0.173 \\
\hline 72 & 0.387 & 0.422 & 0.442 & 0.465 & 0.480 & 0.027 & 0.063 & 0.098 & 0.129 & 0.167 \\
\hline 74 & 0.376 & 0.410 & 0.429 & 0.451 & 0.467 & 0.024 & 0.058 & 0.093 & 0.122 & 0.159 \\
\hline 76 & 0.370 & 0.403 & 0.422 & 0.444 & 0.460 & 0.022 & 0.053 & 0.088 & 0.117 & 0.152 \\
\hline 78 & 0.359 & 0.392 & 0.410 & 0.431 & 0.446 & 0.020 & 0.047 & 0.083 & 0.112 & 0.146 \\
\hline 80 & 0.351 & 0.385 & 0.400 & 0.419 & 0.432 & 0.018 & 0.043 & 0.078 & 0.107 & 0.142 \\
\hline 82 & 0.342 & 0.375 & 0.390 & 0.409 & 0.423 & 0.016 & 0.040 & 0.073 & 0.102 & 0.136 \\
\hline 84 & 0.331 & 0.363 & 0.379 & 0.398 & 0.413 & 0.014 & 0.038 & 0.069 & 0.096 & 0.131 \\
\hline 86 & 0.325 & 0.355 & 0.371 & 0.390 & 0.403 & 0.013 & 0.036 & 0.066 & 0.092 & 0.126 \\
\hline 88 & 0.319 & 0.349 & 0.365 & 0.383 & 0.394 & 0.012 & 0.034 & 0.064 & 0.089 & 0.121 \\
\hline
\end{tabular}

Table 16. Correlations in case of clay - saturated seismic case.

\begin{tabular}{|c|c|c|c|c|c|}
\hline \multicolumn{5}{|c|}{ Clay } \\
\hline & M1 & M2 & M3 & M4 & M5 \\
\hline FS & $0.701-0.004 * \beta$ & $0.760-0.005 * \beta$ & $0.795-0.005 * \beta$ & $0.840-0.005 * \beta$ & $0.871-0.005 * \beta$ \\
\hline
\end{tabular}


Table 17. Correlations in case of clayey sand - saturated seismic case.

\begin{tabular}{|c|c|c|c|c|c|}
\hline \multicolumn{5}{|c|}{ Clayey Sand } \\
\hline & M6 & M7 & M8 & M9 & M10 \\
\hline FS & $0.099-0.001 * \beta$ & $0.198-0.002 * \beta$ & $0.262-0.002 * \beta$ & $0.317-0.003 * \beta$ & $0.372-0.003 * \beta$ \\
\hline
\end{tabular}

Tables 16 and 17 shows the correlation equations in case of clay and clayey sand respectively for all the ten types of materials in case of saturated seismic analysis.

From Table 16, the final average correlation between FS and $\beta$ in case of clay came out to be:

$$
\mathrm{FS}=0.793-0.005 * \beta
$$

Also from Table 17, the final average correlation between FS and $\beta$ in case of clayey sand came out to be:

$$
\mathrm{FS}=0.25-0.002 * \beta
$$

The coefficient of determination $\mathrm{R}^{2}$ in equation (7) and (8) is $99.7 \%$ which shows the variables are best correlated with each other.

A very similar work is also done to develop correlations [24]. These correlations are very useful to apply when the factor of safety, shear strength or any other value such as cohesion, friction or unit weight etc. is required to geotechnical engineers. The results of simple reliability analyses are neither more accurate nor less accurate than factors of safety calculated using the same types of data, judgments, and approximations.
Although neither deterministic nor reliability analyses are precise, they both have value, and each enhances the value of the other. The simple types of reliability analyses described in this paper require only modest extra effort compared to that required to calculate correlations of factors of safety with all other parameters and hence they can add considerable value to the results of slope stability analyses.

\section{Phase 5: Case Study - Landslide in Karachi, Pakistan}

Heavy rainfall started in Sindh and Baluchistan from the 6 August and continued till the 7 August 2020 with intermissions. Continuous rain over a period of 24 hours caused massive flooding in Karachi, Hyderabad, Shaheed Benazirabad and Dadu of Sindh province. However, Tehsil Johi in Dadu district is the area which is greatly affected by flash floods. It has been reported that floods are not only damaging infrastructures and houses but also destroyed crops in Johi Tehsil. Government of Sindh has declared 80 villages in Dadu district as "Calamity Affected Areas" [25]. The affected areas can be seen in Fig. 9.

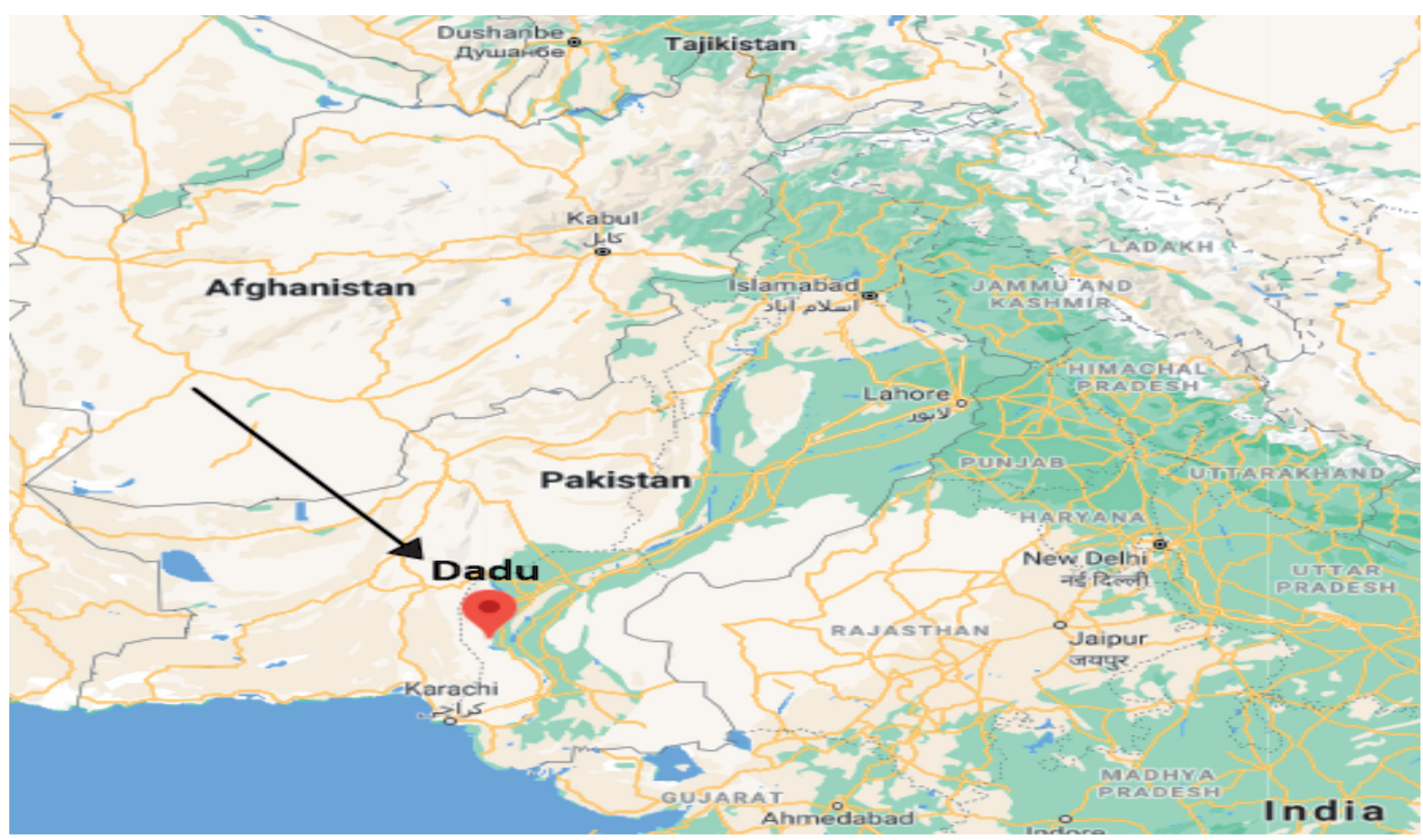

Fig. 9. Affected areas due to floods 2020 in Pakistan. 
During this flood, a landslide occurs at the Gulistane-Johar city of Karachi. This landslide damaged 22 to 30 cars as they were standing at the bottom of parking lot near the landslide hill. The site of this landslide was basically serving as parking lot to the residents of the area. Fortunately no death or injury was reported due to this vary landslide. A video of this landslide is also recorded by a nearby resident and is available online. Figs 10-13 show some different views of the landslide.

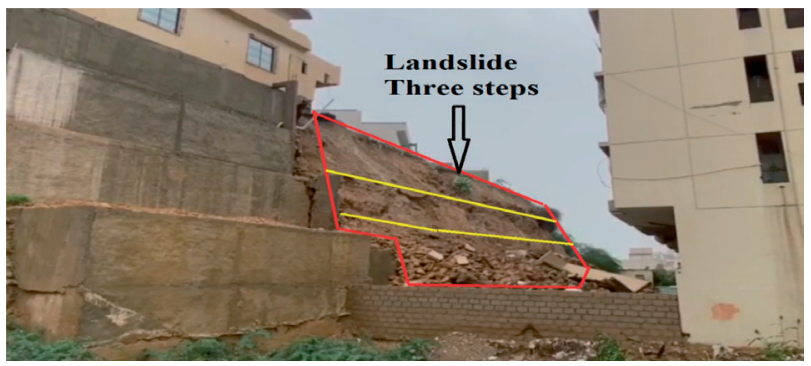

Fig. 10. Gulistan-e-Johar Landslide 2020 view which show three slipped steps.

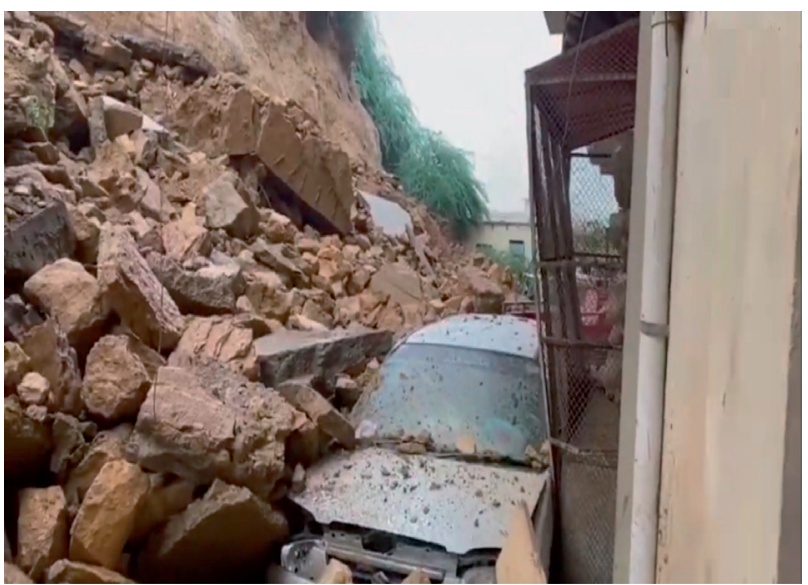

Fig. 11. Gulistan-e-Johar Landslide 2020 view showing one of the damaged car.

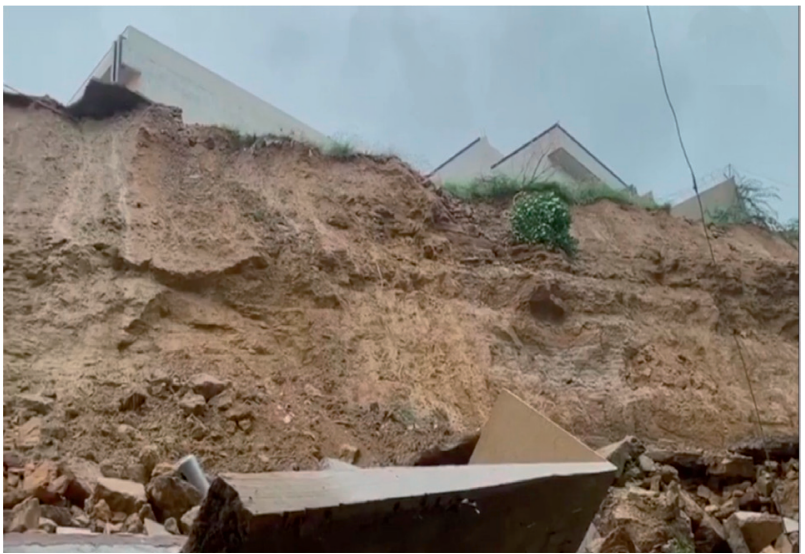

Fig. 12. Gulistan-e-Johar Landslide 2020 view from front side.
Apart from the landslide, the floods also caused a huge damage to crops and affected many people. Severity of the flood can be seen in Figs 14 and 15:

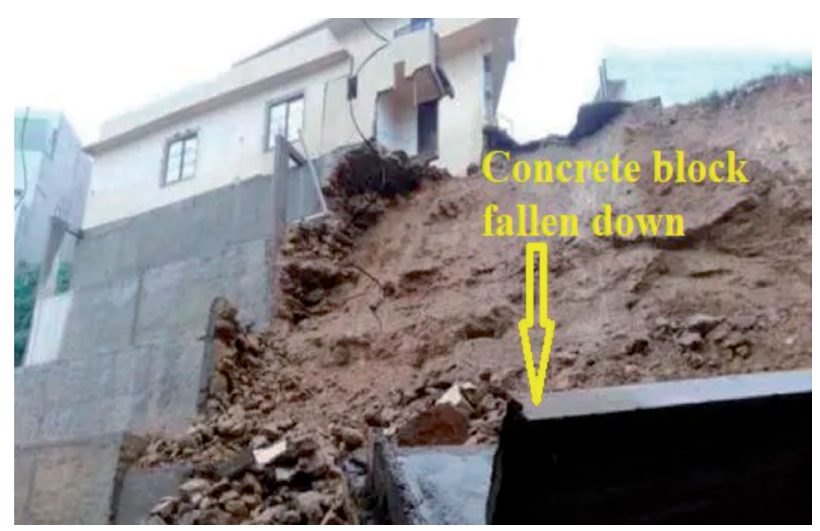

Fig. 13. Gulistan-e-Johar Landslide 2020 concrete block fallen down.

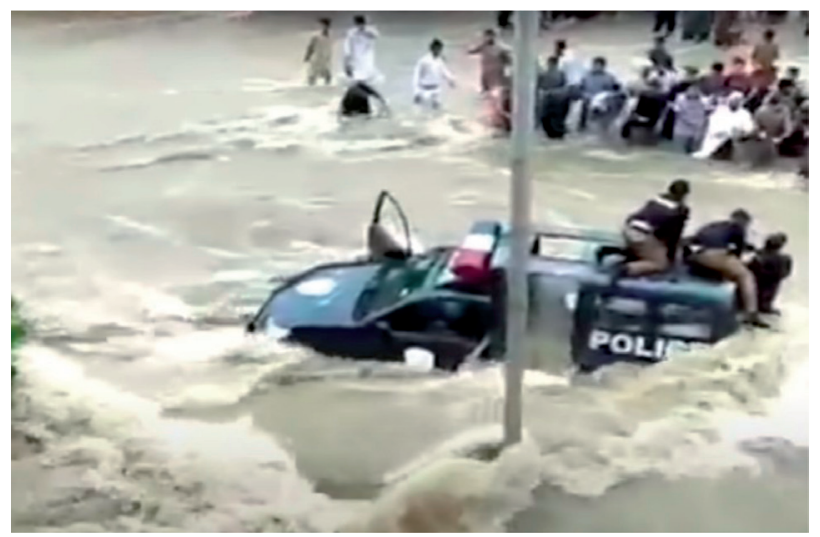

Fig. 14. A police van stuck in water during the flood August 2020 at Karachi.

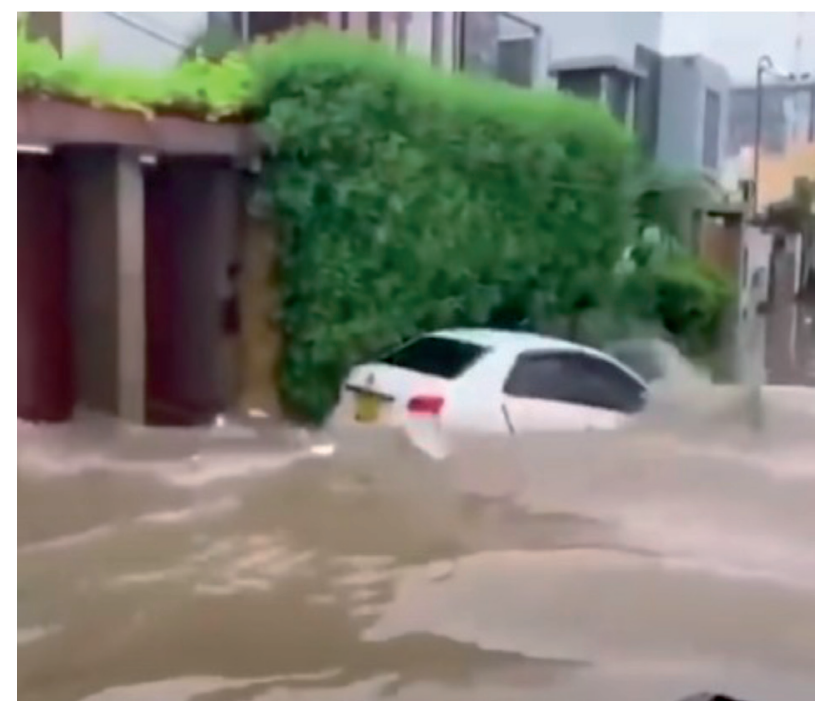

Fig. 15. Car stuck in water during the flood August 2020 at Karachi. 


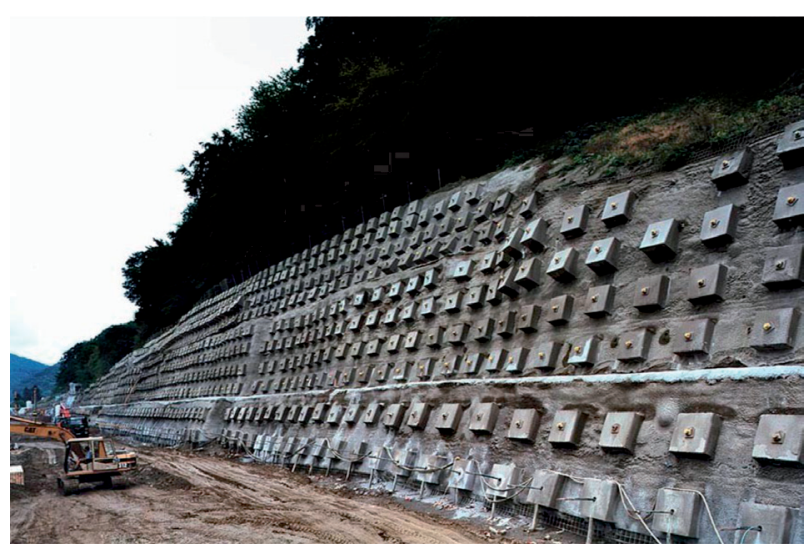

Fig. 16. General overview of slope nailing technique.

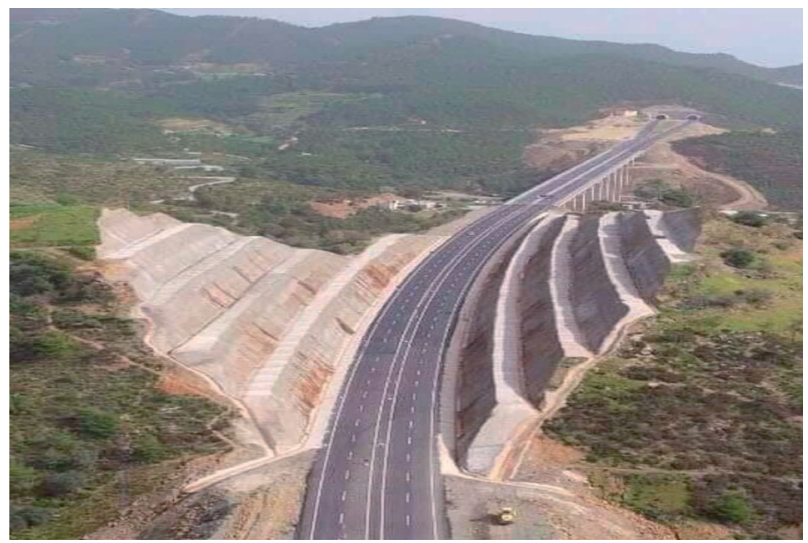

Fig. 17. General overview of slope stepping technique.

In one of the report [26] by European Commission's Directorate-General for European Civil Protection and Humanitarian Aid Operations says:

- Monsoon rains and associated flooding continue to affect Pakistan, resulting in at least 163 fatalities, and more than 100 injured, as reported by national authorities on 30 August. More than 1,590 houses, nine bridges and 10 roads were damaged or destroyed.

- Over 20-29 August, heavy rain and urban flooding occurred in Karachi City (Sindh Province), leading to at least 27 fatalities and 13 injured. National authorities are carrying out rescue and relief activities, while food items have been distributed to the affected population.

- Heavy rain is forecast over most of Punjab, northern Khyber Pakhtunkhwa, Gilgit-Baltistan, and AJK Regions on 31 August - 1 September.

After collecting soil samples from the landslide site and tested in soil laboratory, the material properties were found similar as mentioned in table 1 . The failed slope is modelled in Slide and back analysis is performed. Applying the correlations mentioned in equations $1,2,10,11,12,13,14$ and 15 , it is concluded that the slope factor of safety at the time of failure was less than 1. All such landslides can be controlled by analyzing the slope on time and fix it by either stepping technique or nailing. Figs 16 and 17 shows stepping and nailing technique.

The equations developed in this paper can contribute in it. This type of evaluation was not made in past because only FS were computed to guide the design. Now the FS value can be compared with all other parameters using all these correlations developed in this paper. This research is applicable for clay and clayey sand only. For all other soil types, it is recommended to develop new correlations.

\section{Conclusions}

The following conclusions are drawn from this research work:

1. The slope angle and factor of safety have a closure relationship with each other. More the slope angle, less will be the factor of safety. This variation can be observed in equations $1,2,10,11,12,13,14$ and 15.

2. These correlations are the main outcome of this work. And they can be used to find the value of FS with any varying slope angle $(\beta)$. By using these equations, a geotechnical engineer can calculate the optimum FS value while designing any slope.

3. Engineers can apply these correlations in designing an earthen dam or slope designing in mountainous regions while building a road adjacent to the mountain provided that the material properties and slope geometries are similar as considered in this paper.

4. These equations are applicable for homogenous slopes only. The material properties must be in the range of Table 1.

5. Future work can be done in case of non-homogenous slopes as well as complex shape slopes to get the correlations between different soil parameters, FS and $\beta$.

6. $\tau=\mathrm{c}+\tan \phi$, using this equation, the correlations between shear strength and shear stress can be calculated in any future work.

7. Severe rainfall causes floods especially in urban and developed areas and ultimately it damages property and causes great human loss. One of such incident happened in Gulistan-e-Johar area of Karachi city on August 24, 2020. The landslide damages 22 to 30 cars and fortunately no human death or injury was reported. The correlations from equation 1 to 9 shows that the FS at the time of failure was less than 1 . The slope angle must be kept at lower value in future to minimize such failure.

\section{Acknowledgements}

This work was conducted with supports from the National Natural Science Foundation of China (Grant Nos. U1602232 and 51474050), Doctoral 
Scientific Research Foundation of Liaoning Province (Grant No. 20170540304 and 20170520341), China Scholarship Council (Grant No. 201806080103), Key Research and Development Program of Science and Technology in Liaoning Province, China (Grant No. 2019JH2/10100035), the Fundamental Research Funds for the Central Universities (Grant No. N170108029).

\section{Conflict of Interest}

The authors declare no conflict of interest.

\section{References}

1. SAKELLARIOU M.G., FERENTINOU M.D. A study of slope stability prediction using neural networks. Geotech. Geol. Eng. 23, 419, 2005.

2. HOEK E., BRAY J.W. Rock Slope Engineering. Revised 3rd Edition, The Institution of Mining and Metallurgy, London, 341, 1981.

3. AHANGAR-ASR A., FARAMARZI A., JAVADI A.A. A new approach for prediction of the stability of soil and rock slopes. Eng. Comput. 27 (7), 878, 2010.

4. MOHAMED T., KASA A., MUKHLISIN M. Prediction of slope stability using statistical method and fuzzy logic. Online J. Sci. Technol. 2 (4), 68, 2012a

5. MOHAMED T., KASA A., TAHA M.R. Fuzzy logic system for slope stability prediction. Int. J. Adv. Sci. Eng. Inform Technol. 2 (2), 38, 2012b.

6. ERZIN Y., CETIN T. The use of neural networks for the prediction of the critical factor of safety of an artificial slope subjected to earthquake forces. Scientia Iranica. 19 (2), 188, 2012.

7. CHAE B.G., LEE J.H., PARK H.J., CHOI J. A method for predicting the factor of safety of an infinite slope based on the depth ratio of the wetting front induced by rainfall infiltration. Nat. Hazards Earth Syst. Sci. 15, 1835, 2015.

8. FIRMANSYAH TOHARI A., LATIEF F.D. Prediction of landslide run-out distance based on slope stability analysis and center ofmass approach. IOP Conf. Ser: Earth Environ. Sci. 29, 1, 2016.

9. ZHANG M., NIE L., XU Y., DAI D. A thrust load-caused landslide triggered by excavation of the slope toe: a case study of the Chaancun Landslide in Dalian City, China. Arab. J. Geosci., 8, 6555, 2015.

10. OH S., LEE G., BAE W. Estimation of landslide risk based on infinity flow direction. J. Korean Geo-Environ. Soc. 20 (2), 5, 2019.

11. CHO S.E. Probabilistic stability analysis of rainfallinduced landslides considering spatial variability of permeability. Eng. Geol., 171, 11, 2014.
12. LEE S., JEONG G., PARK S.J. Evaluating geomorphological classification systems to predict the occurrence of landslides in mountainous region. J. Korean Geogr. Soc. 50 (5), 485, 2015.

13. LEPORE C., KAMAL S.A., SHANAHAN P., BRAS R.L. Rainfall-induced landslide susceptibility zonation of Puerto Rico. Environ. Earth Sci. 66 (6), 1667, 2012.

14. WANG J., NIE G., XUE C. Landslide displacement prediction based on time series analysis and data assimilation with hydrological factors. Arab. J. Geosci. 13, 460, 2020.

15. BAI S., WANG J., THIEBES B., CHENG C., YANG Y. Analysis of the relationship of landslide occurrence with rainfall: a case study of Wudu County, China. Arab. J. Geosci. 7, 1277, 2014.

16. SUJATHA E.R., RAJAMANICKAM V., KUMARAVEL P., SARANATHAN E. Landslide susceptibility analysis using probabilistic likelihood ratio model - a geospatialbased study. Arab. J. Geosci. 6, 429, 2013.

17. DUNCAN J.M., WRIGHT S.G. Soil strength and slope stability. John Wiley \& Sons, Inc. 201, 2005.

18. DAVID R.M., KEVIN S.M. HARVEY M.G., WILLIAM E.D. Forest clearing and regional landsliding. Geology. 28 (4), 311, 2000.

19. KIM J., SHIN H. Slope stability assessment on a landslide risk area in Ulsan during rainfall. J. Korean Geotech. Soc. 32 (6), 27, 2016.

20. JEONG S., LEE K., KIM J., KIM Y. Analysis of rainfallinduced landslide on unsaturated soil slopes. Sustainability. 9 (7), 1280, 2017.

21. RAN Q., HONG Y., LI W., GAO J. A modelling study of rainfall-induced shallow landslide mechanisms under different rainfall characteristics. J. Hydrol. 563, 790, 2018.

22. HONG H., CHEN W., XU C., YOUSSEF A. M., PRADHA B., BUI D. T. Rainfall-induced landslide susceptibility assessment at the Chongren area (China) using frequency ratio, certainty factor, and index of entropy. Geocarto Int. 32 (2), 139, 2017.

23. TANG G., HUANG J., SHENG D., SLOAN S.W. Stability analysis of unsaturated soil slopes under random rainfall patterns. Eng. Geol. 245, 322, 2018.

24. KHAN M. I., WANG S. Comparative study of seismic and non-seismic analysis of a soil slope to develop correlations for factor of safety considering horizontal and vertical seismic coefficients. Earth and Environmental Science, 2020 4th International Conference on Sustainable Energy Engineering 23-25 May 2020, Beijing, China. 529, 2020.

25. SOCIETIES IFORCARC. Emergency Plan of Action (EPOA) Pakistan: Monsoon Floods. 2020.

26. EUROPEAN COMMISSION'S DIRECTORATE GENERAL FOR EUROPEAN CIVIL PROTECTION AND HUMANITARIAN AID OPERATIONS. A report on 31 August, 2020. 